\title{
STRATEGI PEMASARAN PAKET INBOUND TOUR: STUDI KASUS DI PT. LOTUS ASIA TOURS JIMBARAN BALI
}

\author{
Camelia Agatha Mahayu Putri \\ I Putu Sudana \\ I GPB. Sasrawan Mananda \\ Email : cameliagatha@gmail.com \\ PS. S1 Industri Perjalanan Wisata \\ Fakultas Pariwisata UNUD
}

\begin{abstract}
ABSTRAK
Tujuan penelitian ini adalah untuk mengetahui faktor internal yaitu kekuatan dan kelemahan dan eksternal yaitu peluang dan ancaman dari PT. Lotus Asia Tours serta untuk mengetahui strategi yang dapat dilakukan pihak PT. Lotus Asia Tours untuk memasarkan paket inbound tour. Lokasi penelitian dilakukan di PT. Lotus Asia Tours yang terletak di Jl. By Pass Ngurah Rai No. 18, Jimbaran Bali.. Penelitian ini menggunakan metode deskriptif kualitatif. Teknik pengumpulan data dilakukan dengan cara observasi, wawancara, studi kepustakaan, studi dokumentasi dan didukung dengan daftar pertanyaan yang disebarkan kepada 60 informan. Daftar pertanyaan yang disebarkan berpedoman pada indikator marketing mix 7 P (product, price, place, promotion, physical evidence, people, process). Hasil data yang diperoleh lalu dianalisis dengan IFAS (Internal Factor Analysis Summary) dan EFAS ( External Factor Analysis Summary), selanjutnya untuk mengetahui posisi perusahaan digunakan matriks internal eksternal dan untuk mengetahui alternatif strategi digunakan matriks SWOT, sehingga dapat menciptakan strategi pemasaran baru serta mengembangkan program-program yang telah ada agar dapat diterapkan oleh PT. Lotus Asia Tours Jimbaran Bali. Berdasarkan hasil penelitian diperoleh total nilai rata-rata lingkungan internal yaitu sebesar 3,01 dan lingkungan eksternal yaitu sebesar 2,96, dapat diketahui bahwa posisi perusahaan berada di sel IV yang berarti stability strategy dimana strategi yang tetapkan tidak merubah arah strategi yang telah ada.
\end{abstract}

Kata Kunci : Marketing mix, Inbound Tour.

\section{PENDAHULUAN}

Indonesia merupakan salah satu negara yang memiliki beragam daya tarik dan pihak pemerintah secara serius memperhatikan perkembangan di sektor pariwisata, dapat dilihat dari beberapa tahun terakhir pemerintah Indonesia sedang mengembangkan serta mempromosikan kepariwisataan yang ada di Indonesia hingga ke mancanegara dengan adanya program pemerintah yaitu "Wonderful Indonesia" yang dicanangkan pada akhir Januari 2011 oleh Menteri Kebudayaan dan Pariwisata waktu itu yang saat itu dijabat oleh Jero Wacik. Konsep "Wonderful Indonesia" menyoroti "Keindahan" alam di Indonesia, budaya, masyarakat.
Bali sendiri merupakan salah satu pulau di Indonesia yang mempunyai potensi di bidang kepariwisataan. Pariwisata Bali menjadi sektor pembangunan yang terus dikembangkan untuk menunjang perekonomian masyarakat Bali. Inbound tour merupakan kegiatan perjalanan berdasarkan ruang lingkup kegiatan perjalanan wisata yang dilakukan oleh wisatawan asing yang datang mengunjungi Indonesia dan Pulau Bali masih menjadi daerah tujuan wisata utama di Indonesia (Yoeti, 1996).

Potensi pariwisata Bali yang berupa alam dan budaya masyarakat Bali akan sulit dipasarkan apabila tidak ditunjang oleh kerjasama yang sinergis antar pelaku bisnis pariwisata di Bali, termasuk kerjasama antar 
Biro Perjalanan Wisata (BPW) dengan pihak penyedia jasa akomodasi atau hotel.

Salah satu biro perjalanan wisata yang ada di Bali yaitu PT. Lotus Asia Tours yang terletak di Jl. By Pass Ngurah Rai No. 18 Jimbaran Bali. PT. Lotus Asia Tours merupakan usaha biro perjalanan wisata yang menangani pengemasan paket wisata, penjualan paket wisata, reservasi hotel, dokumen perjalanan, tour guide service dan juga menyediakan transportasi wisata, serta memiliki pangsa pasar utama yaitu Italia, Jerman, dan Prancis.

Adapun jumlah kunjungan wisatawan mancanegara yang menggunakan paket wisata pada PT. Lotus Asia Tours dalam lima tahun terakhir yaitu pada periode 2010- 2014 dapat dilihat pada Tabel 1.

Tabel 1.

Jumlah Wisatawan Eropa Yang Menggunakan Paket Inbound Tour pada PT. Lotus Asia Tours Tahun 2010 - 2014

\begin{tabular}{|c|c|c|c|}
\hline No & Tahun & $\begin{array}{c}\text { Jumlah } \\
\text { Wisatawan }\end{array}$ & $\begin{array}{c}\text { Pertumbuhan } \\
\text { (\%) }\end{array}$ \\
\hline 1. & 2010 & 4.942 & - \\
\hline 2. & 2011 & 4.754 & $-3,80$ \\
\hline 3. & 2012 & 6.072 & 27,7 \\
\hline 4. & 2013 & 5.575 & $-8,18$ \\
\hline 5. & 2014 & 5.124 & $-8,08$ \\
\hline \multicolumn{3}{|c|}{ Rata-rata } \\
\hline
\end{tabular}

Sumber : PT. Lotus Asia Tours Jimbaran, Bali, 2015

Berdasarkan Tabel 1.2 dapat diketahui bahwa jumlah kunjungan wisatawan yang menggunakan paket wisata pada PT. Lotus Asia Tours mengalami fluktuasi. Penurunan terjadi pada tahun 2010 sebesar 4.942 orang dan pada tahun 2011 sebesar 4.754 orang( -3,80\%). Namun pada tahun 2012 jumlah wisatawan yang menggunakan paket wisata pada PT. Lotus Asia Tours mengalami peningkatan sebesar 6.072 orang $(27,7 \%)$, pada tahun 2013 sebesar 5.575 $(-8,18 \%)$ dan di tahun 2014 sebesar 5.124 orang $(-8,08 \%)$ dan jumlah rata-rata pertumbuhan yaitu sebesar 7,64\%. Terjadinya penurunan di tahun 2013 terjadi disebabkan oleh adanya krisis ekonomi Eropa di tahun 2008 belum sepenuhnya pulih akibat kegagalan Uni Eropa uantuk memperbaiki perbankan dan dipicu oleh besarnya utang pemerintah di negara-negara Eropa dan terjadi lagi di tahun 2013.

Dari beberapa masalah yaitu terjadinnya fluktuasi jumlah tamu mancanegara dan maka dari itu, penulis tertarik untuk mengetahui apa saja strategi pemasaran paket inbound tour yang telah dilakukan oleh PT. Lotus Asia Tours. Serta untuk mengetahui strategi pemasaran paket inbound tour yang dapat dilakukan oleh PT. Lotus Asia Tours.

\section{METODE}

Penelitian ini menggunakan metode deskriptif kualitatif yaitu dengan menguraikan dan menjelaskan tentang strategi pemasaran yang akan dilakukan oleh PT. Lotus Asia Tours. Lokasi penelitian dilaksanakan di PT. Lotus Asia Tours yang terletak di Jl. By Pass Ngurah Rai No. 18, Jimbaran Bali.

Sampel yang digunakan dalam penelitian ini berjumlah 60 informan. Teknik pengumpulan data data yang digunakan oleh penulis yaitu wawancara, observasi, daftar pertanyaan, studi kepustakaan, dan studi dokumentasi 
Vol. 3 No. 2, 2015

\section{HASIL DAN PEMBAHASAN}

Berikut ini disajikan hasil dari rating, bobot, dan skor IFAS PT. Lotus Asia Tours dapat dilihat pada Tabel 2.

Tabel 2

Rating, Bobot, dan Skor IFAS PT. Lotus Asia Tours

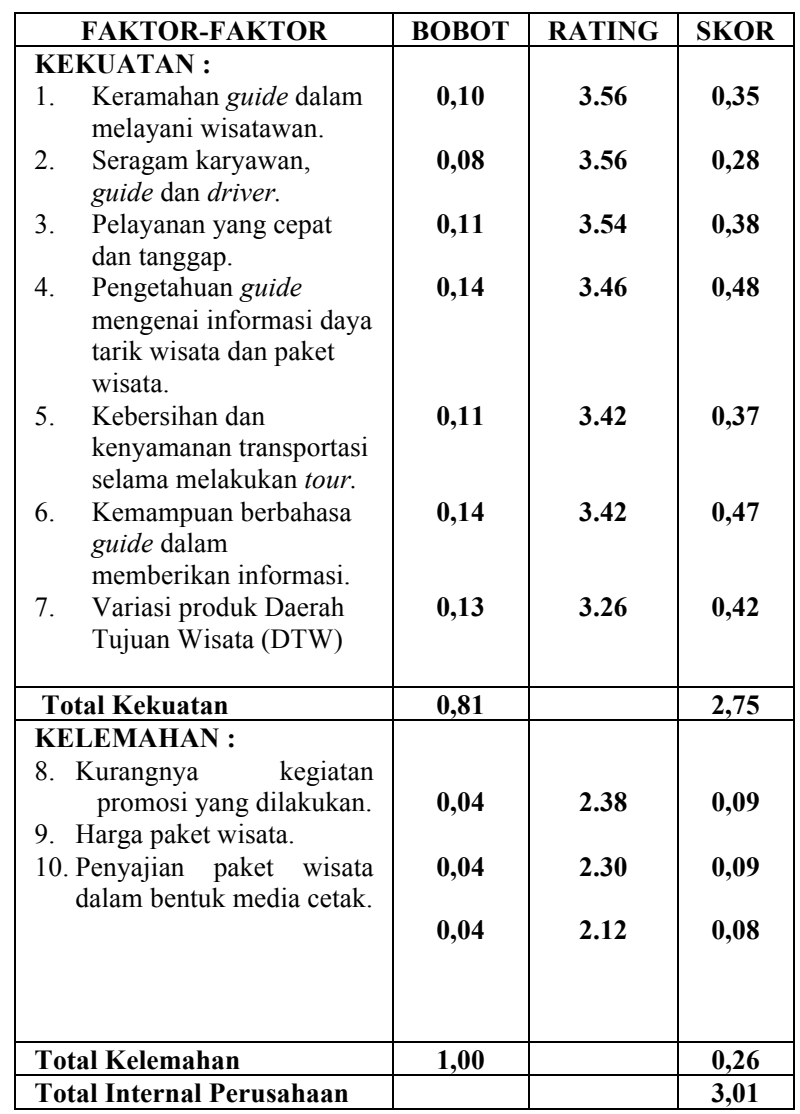

Berikut ini disajikan hasil matriks IE PT. Lotus Asia Tours dapat dilihat pada Tabel 4.

Tabel 4

Matriks IE PT. Lotus Asia Tours

4

$\operatorname{IFAS}(3,01) \quad 3 \quad 2$

\begin{tabular}{|c|c|c|c|}
\hline Tinggi & $\begin{array}{c}\mathrm{I} \\
\text { GROWTH } \\
\text { Konsentrasi melalui } \\
\text { integrasi vertikal }\end{array}$ & $\begin{array}{c}\text { II } \\
\text { GROWTH } \\
\text { Konsentrasi } \\
\text { melalui integrasi } \\
\text { hoizontal } \\
\end{array}$ & $\begin{array}{c}\text { III } \\
\text { RETRENCHMENENT } \\
\text { Turnarround }\end{array}$ \\
\hline $\begin{array}{l}\text { EFAS } \\
(2,96) \\
\text { Sedang }\end{array}$ & $\begin{array}{c}\text { IV } \\
\text { STABILITY } \\
\text { Hati-hati } \\
\end{array}$ & $\begin{array}{c}\mathrm{V} \\
\text { GROWTH } \\
\text { STABILITY }\end{array}$ & $\begin{array}{c}\mathrm{VI} \\
\text { RETRENCHMENENT } \\
\text { Captive Company }\end{array}$ \\
\hline $\begin{array}{l}\text { Rendah } \\
1\end{array}$ & $\begin{array}{c}\text { VII } \\
\text { GROWTH } \\
\text { Diversifikasi } \\
\text { Konsentris }\end{array}$ & $\begin{array}{c}\text { VIII } \\
\text { GROWTH } \\
\text { Diversifikasi } \\
\text { Konglomerat }\end{array}$ & $\begin{array}{c}\text { IX } \\
\text { RETRENCHMENENT } \\
\text { Bangkrut/ likuidasi }\end{array}$ \\
\hline
\end{tabular}

Berikut ini disajikan hasil dari rating, bobot dan skor EFAS PT. Lotus Asia Tours dapat dilihat pada Tabel 3.

Tabel 3

Rating, Bobot, dan Skor EFAS PT. Lotus Asia Tours

\begin{tabular}{|c|c|c|c|}
\hline FAKTOR-FAKTOR & ВОВОТ & RATING & SKOR \\
\hline PELUANG : & & & \\
\hline $\begin{array}{l}\text { 1. Supplier (hotel, restoran, } \\
\text { daya tarik wisata) } \\
\text { semakin beragam }\end{array}$ & 0.08 & 4 & 0.40 \\
\hline $\begin{array}{l}\text { 2. Berkembangnya media } \\
\text { internet }\end{array}$ & 0.07 & 4 & 0.56 \\
\hline $\begin{array}{l}\text { 3. Adanya pameran- } \\
\text { pameran yang } \\
\text { dilaksanakan pemerintah }\end{array}$ & 0.14 & 3.8 & 0.38 \\
\hline $\begin{array}{l}\text { 4. Kegiatan pemerintah } \\
\text { (APEC dan WTO) }\end{array}$ & 0.12 & 3.8 & 0.30 \\
\hline $\begin{array}{l}\text { 5. Alat Komunikasi terus } \\
\text { berkembang }\end{array}$ & 0.05 & 3.6 & 0.43 \\
\hline $\begin{array}{l}\text { 6. Jumlah kunjungan } \\
\text { wisatawan meningkat }\end{array}$ & 0.11 & 3.4 & 0.37 \\
\hline Total Peluang & $\mathbf{0 , 5 7}$ & & 2.44 \\
\hline ANCAMAN : & & & \\
\hline $\begin{array}{l}\text { 7. Kenaikan harga Bahan } \\
\text { Bakar Minyak }\end{array}$ & 0.06 & 2.6 & 0.15 \\
\hline $\begin{array}{l}\text { 8. Adanya krisis ekonomi } \\
\text { global }\end{array}$ & 0.06 & 2.4 & 0.14 \\
\hline $\begin{array}{l}\text { 9. } \begin{array}{c}\text { Pertumbuhan } \\
\text { perjalanan wisata }\end{array} \\
\text { biro }\end{array}$ & 0.10 & 2.2 & 0.15 \\
\hline $\begin{array}{l}\text { 10. Berkembangnya online } \\
\text { travel agent }\end{array}$ & 0.10 & 1.6 & 0.08 \\
\hline Total Ancaman & & & 0.52 \\
\hline Total Eksternal Perusahaan & 1.00 & & 2.96 \\
\hline
\end{tabular}

Berdasarkan hasil dari rating, bobot dan skor dari internal faktor dapat dijelaskan bahwa yang menjadi kekuatan dari PT. Lotus Asia Tours yang memiliki rating paling tinggi yaitu keramahan guide dalam melayani wisatawan dan seragam karyawan, guide dan drive sama-sama mendapat nilai tertinggi sebesar 3,56. Kemudian pelayanan yang cepat dan tanggap mendapatkan rating 3,54. Pengetahuan guide mengenai informasi daya tarik wisata dan paket wisata mendapat rating $\mathbf{3 , 4 6}$. Kebersihan dan kenyamanan transportasi selama melakukan tour dan kemampuan berbahasa guide dalam memberikan informasi sama-sama mendapat rating 3,42. Variasi DTW (daya tarik wisata) mendapat rating $\mathbf{3 , 2 6}$. 
Untuk faktor internal kelemahan pada PT. Lotus Asia Tours terdapat tiga indikator yang pertama yaitu harga paket wisata mendapat rating 2,30. Selanjutnya kurangnya promosi yang dilakukan mendapat rating $\mathbf{2 , 3 8}$. Penyajian paket wisata dalam bentuk broshur sebagai saluran distribusi (place) ini mendapat rating 2,12 .

Berdasarkan hasil dari rating, bobot dan skor dari eksternal faktor dapat dijelaskan bahwa yang menjadi peluang dari PT. Lotus Asia Tours yang memiliki rating paling tinggi yaitu berkembangnya media internet dan suppliersupplier (hotel, restoran, daya tarik wisata) sama-sama mendapat rating 4. Selanjutnya adanya pameran-pameran yang dilaksanakan pemerintah dan kegiatan internasional pemerintah (APEC dan WTO) sama-sama mendapat rating 3,8. Alat komunikasi terus berkembang mendapat rating 3,6. Jumlah kunjungan wisatawan meningkat mendapat rating $\mathbf{3 , 4}$.

Faktor eksternal yang merupakan ancaman yaitu meningkatan harga bahan bakar minyak (BBM) mendapat rating 2,6. Selanjutnya adanya krisis ekonomi global mendapat rating sama yaitu sebesar $\mathbf{2 , 4}$. Lalu berkembangnya BPW mendapat rating 2,2. Yang terakhir yaitu berkembangnya online travel agent mendapat rating 1,6 dengan berkembangnya online travel agent juga menjadi saingan bagi perusahaan.

Berdasarkan hasil yang diperoleh dari matrik EFE dan matrik IFE maka dapat disusun selanjutnya dalam matriks internal eksternal (IE). Matriks IE digunakan untuk menganalisis posisi perusahaan secara lebih detail dan melihat strategi apa yang tepat untuk diterapkan oleh perusahaan. Hasil dari penilaian matriks IE untuk PT. Lotus Asia Tours dapat dilihat pada diagram 3.1. Nilai total IFAS sebesar $\mathbf{3 , 0 1}$ dan EFAS sebesar $\mathbf{2 , 9 6}$ menunjukkan posisi PT. Lotus Asia Tours berada pada sel IV. Pada posisi ini strategi yang tanpa mengubah arah strategi yang telah diterapkan.

\section{Strategi Pemasaran Paket Inbound Tour yang telah dilakukan PT. Lotus Asia Tours}

1. PT. Lotus Asia Tours telah melakukan strategi promosi paket inbound tour yang dimiliki yaitu dengan mengikuti pameran-pameran dan travel fair.
2. PT. Lotus Asia Tours telah membuka sistem online booking di awal 2015.

3. Mengembangkan Sumber Daya Manusia, dengan cara melakukan adanya training terhadap sistem reservasi yang baru di tetapkan.

\section{Strategi Pemasaran Paket Inbound Tour Yang Akan Dilakukan oleh PT. Lotus Asia Tours}

Berdasarkan Matriks SWOT tersebut maka didapatkan 4 (empat) langkah alternatif strategi yaitu sebagai berikut :

1. Strategi SO

Strategi SO yang ditempuh oleh PT. Lotus Asia Tours yaitu :

a) Memperluas kerja sama dengan travel agent luar negri dan suppliersupplier seperti hotel, restoran, dan daya tarik wisata baru.

b) Menciptakan dan mengembangkan produk dan wisata bervariasi yang berbasis budaya dan alam sesuai dengan karakteristik wisatawan yang bersifat venturers / allocentric tourist yaitu wisatawan yang menyukai hal- hal baru menurut Plog (dalam Robinson et.all,2011). Mempertahankan kualitas pelayanan cepat dan tanggap seperti mulai dari proses booking serta pada saat tour.

c) Mempertahankan produk transportasi yang bersih serta nyaman.

2. Strategi ST

Strategi ST yang dapat ditempuh oleh PT. Lotus Asia Tours yaitu :

a) Memperluas kerja sama dengan agent-agent luar negri dan suppliersupplier (hotel, restoran, dan daya tarik wisata).

b) Mempertahankan kualitas produk dan pelayanan yang cepat dan tanggap serta staf yang ramah.

c) Mengoptimalkan online booking yang sudah ada, agar dapat bersaing dengan online travel agent lainya seperti hotel bed dan booking.com.

3. Strategi WO

Strategi WO yang ditempuh oleh PT. Lotus Asia Tours antara lain: 
a) Meningkatkan kegiatan promosi paket inbound tour melalui website, atau membuat website khusus Lotus Asia Tours Bali, karena website selama ini masih menggunakan website bersama dengan cabang lotus enterprises di Malaysia, Singapore, Myanmar.

b) Mengikuti kegiatan Travel Fair dengan rutin.

c) Melakukan kerja sama dengan supplier-supplier seperti hotel, restoran, daya tarik wisata baru.

4. Strategi WT

Strategi WT ditempuh oleh PT. Lotus Asia Tours antara lain :

a) Menyajikan produk paket dengan media cetak seperti broshur dan majalah agar lebih menarik.

b) Memaksimalkan kegiatan promosi dengan rutin seperti mengikuti travel fair.

c) Mengoptimalkan online booking yang sudah ada agar dapat bersaing dengan online travel agent lainya seperti hotel bed dan booking.com

d) Harga paket wisata yang ditawarkan perlu disesuaikan dengan persepsi wisatawan dan keadaan eksternal yang ada.

e) Memperluas pangsa pasar tidak terbatas Italia, Prancis, Jerman.

\section{SIMPULAN DAN SARAN}

Berdasarkan pembahasan mengenai strategi pemasaran paket Inbound Tour yang telah dilakukan oleh PT. Lotus Asia Tours dan strategi yang dapat dilakukan oleh PT. Lotus Asia Tours dengan analisis IFAS dan juga analisis EFAS, matriks Internal Eksternal (IE) yang kemudian dikombinasikan dengan matriks SWOT ,maka dapat disimpulkan bahwa:

1. Strategi pemasaran paket inbound tour yang sudah dilakukan oleh PT. Lotus Asia Tours :

a. PT. Lotus Asia Tours telah melaksanakan strategi promosi paket inbound tour yang dimiliki yaitu dengan mengikuti travel fair dan memiliki website.

b. PT. Lotus Asia Tours membuka sistem online booking, mengingat semakin banyaknya persaingan dari online travel agent.

c. Mengembangkan Sumber Daya Manusia, hal ini dilakukan untuk meningkatkan kualitas kerja dengan cara mengadakan a training terhadap sistem TechDMC kepada seluruh staf, dan mengadakan staff gathering di setiap tahun.

2. Posisi perusahaan di ukur dari matriks Internal Eksternal (IE) berada pada sel IV yang artinya strategy stability dimana pada posisi ini strategi yang tanpa mengubah arah strategi yang telah diterapkan.

3. Strategi pemasaran yang dapat dilakukan oleh PT. Lotus Asia Tours yaitu :

a. Sesuai dengan analisis SWOT, maka dapat diketahui bahwa posisi pada PT. Lotus Asia Tours pada diagram matriks internal eksternal berada pada kuadrat IV yang menunjukan stability strategy.

b. Strategi ini didasarkan pada kegiatan yang bersifat defensif dan berusaha meminimalkan kelemahan yang ada serta menghindari ancaman. Strategi WT ditempuh oleh PT. Lotus Asia Tours antara lain :
a) Menyajikan produk paket dengan broshur agar lebih menarik.
b) Memaksimalkan kegiatan promosi.
c) Mengoptimalkan online booking.

Berdasarkan kelemahan yang dimiliki oleh PT. Lotus Asia Tours maka dapat diberikan beberapa saran yang bermanfaat antara lain :

a) Harga yang ditawarkan seharusnya bersaing dengan Biro Perjalanan wisata lain yang menjadi pesaing, dan harga juga harus disesuaikan dengan kebutuhan pasar.

b) Penyajian paket wisata perlu dilakukan secara menarik lewat broshur sehingga wisatawan akan lebih jelas mendapatkan 
informasi paket wisata secara tertulis dan jelas.

c) Perlu peningkatan promosi lewat media cetak seperti majalah yang diterbitkan tiap tahun yang berisi tentang informasi hotel-hotel, restoran, dan daya tarik wisata lainya, sehingga dengan adanya majalah ini diharapkan akan meningkatkan penjualan paket inbound tour di PT. Lotus Asia Tours.

\section{DAFTAR PUSTAKA}

Kotler dan Keller. 2008. Manajemen Pemasaran. Jakarta: PT. Gramedia Pustaka Utama.

PT.Lotus Asia Tours. 2015. Jumlah Kunjungan Wisatawan yang menggunakan paket wisata pada PT. Lotus Asia Tours. Bali : PT. Lotus Asia Tours.

Rangkuti, Freddy. 2013. Analisis SWOT Teknik Membedah Kasus Bisnis. Jakarta : PT. Gramedia Pustaka Utama.

Robbinson, P, (et,all). 2011. Research Themes For Tourism. CAB International.

Yoeti. A. Oka. 2003. Tours and Travel Marketing, Jakarta : PT. Perca.

Yoeti, A Oka. 1996. Pengantar Ilmu Pariwisata. Bandung : Angkasa. 